\title{
Compact Biocompatible Quantum Dots Functionalized for Cellular Imaging
}

\author{
Wenhao Liu ${ }^{1}$, Mark Howarth ${ }^{1,2}$, Andrew B. Greytak ${ }^{1}$, Yi Zheng ${ }^{1}$, Daniel G. Nocera ${ }^{*}$, Alice Y. \\ Ting $^{* 1}$ and Moungi G. Bawendi ${ }^{* 1}$ \\ ${ }^{I}$ Department of Chemistry, Massachusetts Institute of Technology, 77 Massachusetts Ave., Cambridge \\ MA 02139-4307. ' Department of Biochemistry, Oxford University, South Parks Road, Oxford, OX1 3QU, \\ $U K$
}

Email:mgb@mit.edu,ating@mit.edu,nocera@mit.edu

Index

Figure S1. Retention of QY Using Alloyed Shell CdSe/ $Z_{\mathrm{x}} \mathrm{Cd}_{1-\mathrm{x}} \mathrm{S}$ QDs $\quad$ S2

Figure S2. Dynamic Light Scattering $\quad$ S3

Figure S3. pH Stability of 20\% aminoQDs and carboxyQDs $\quad$ S4

Figure S4. Fluorescamine-aminoQD Emission $\quad$ S5

Figure S5. Spectroscopy of 20\% aminoQD-carboxy-X-rhodamine conjugate S6

Figure S6. Conjugation of wild-type streptavidin to 20\% aminoQDs $\quad$ S7

Figure S7. Spectroscopy of 20\% aminoQD-Alexa Fluor 568 conjugate $\quad$ S8

Figure S8. QD-Dye Conjugate Targeting EGF Receptor $\quad$ S9

Movie S1. Receptor tracking with single QD conjugates (filename: SPT_EGF.avi) S10

${ }^{1} \mathrm{H}$ NMR and ESI-MS Characterization of Important Compounds $\quad$ S11-S21 


\section{Retention of QY Using Alloyed Shell CdSe/Zn $\mathrm{Cd}_{1-x} \mathrm{~S}$ QDs}
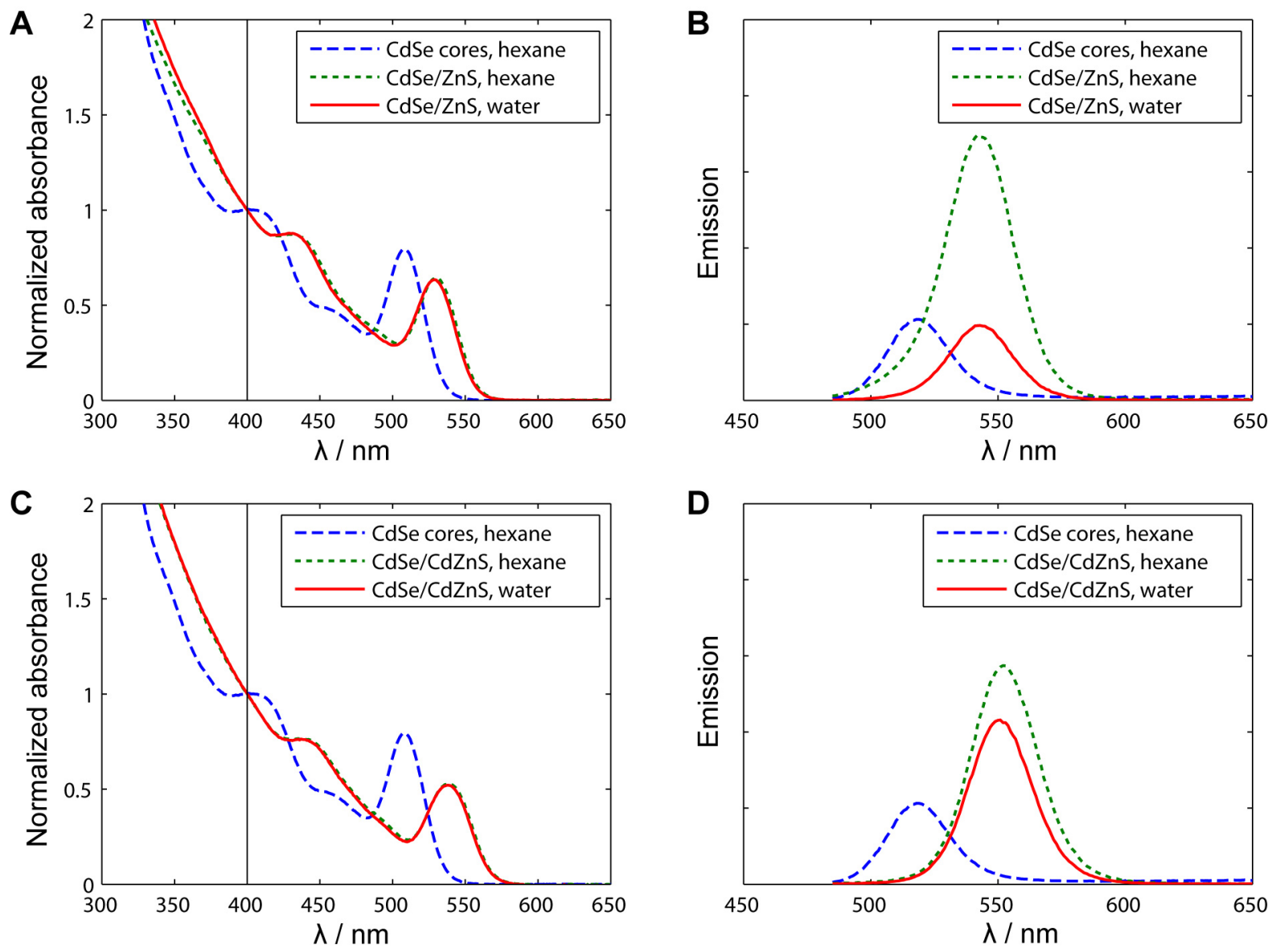

Figure S1. Absorption and emission spectra in hexane and in aqueous solution are shown for a representative batch of CdSe QD cores that was split and separately overcoated with either a pure $\mathrm{ZnS}$ shell or an alloyed $\mathrm{Zn}_{x} \mathrm{Cd}_{1-x} \mathrm{~S}$ shell. (A) Absorption before (- - -) and after (-) growth of a pure ZnS shell (estimated thickness 3 monolayers), and after ligand exchange to make $20 \%$ aminoQDs ( $\cdots)$. Spectra are normalized at $400 \mathrm{~nm}$. (B) Emission spectra of QD samples in (A) under $400 \mathrm{~nm}$ excitation. Spectra are normalized according to their absorbance at $400 \mathrm{~nm}$ such that their intensities may be compared directly. (C) Absorption spectra, normalized as in (A), before and after growth of a $\mathrm{Zn}_{x} \mathrm{Cd}_{1-x} \mathrm{~S}$ shell $(x=0.8)$ and using the same total equivalents of metal precursors as in (A), and after ligand exchange. (D) Emission spectra of QD samples in (C) under $400 \mathrm{~nm}$ excitation, normalized as in (B). 


\section{Dynamic Light Scattering}

A
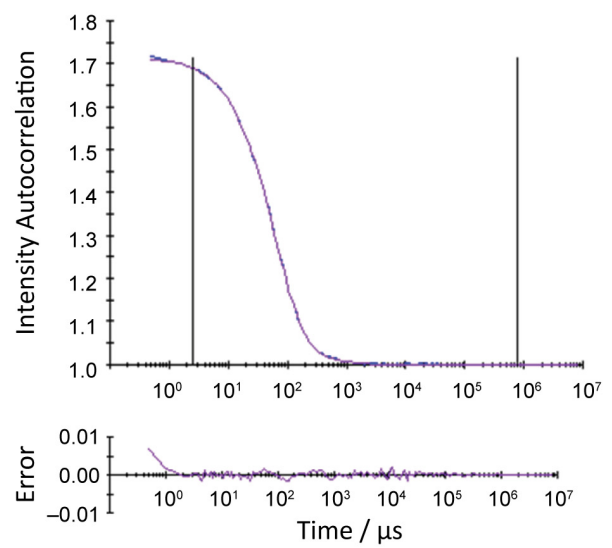

B
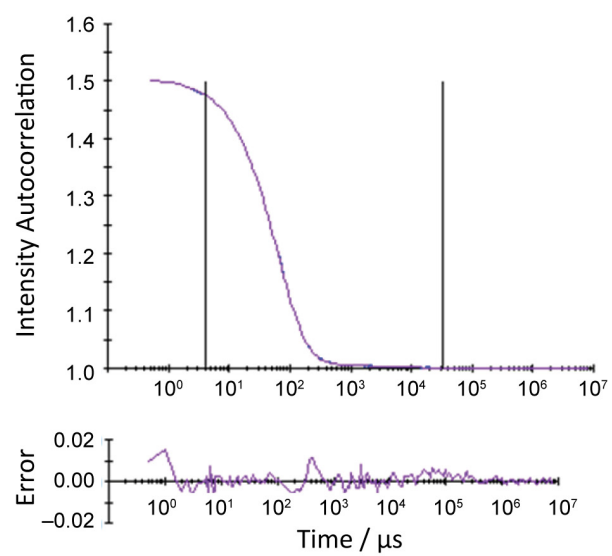

C
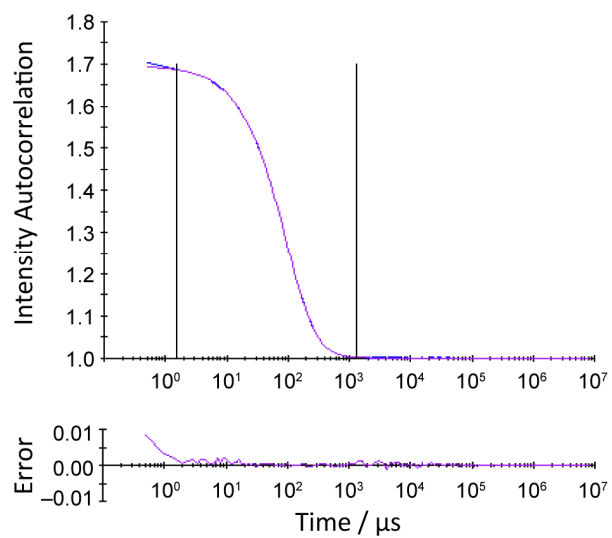

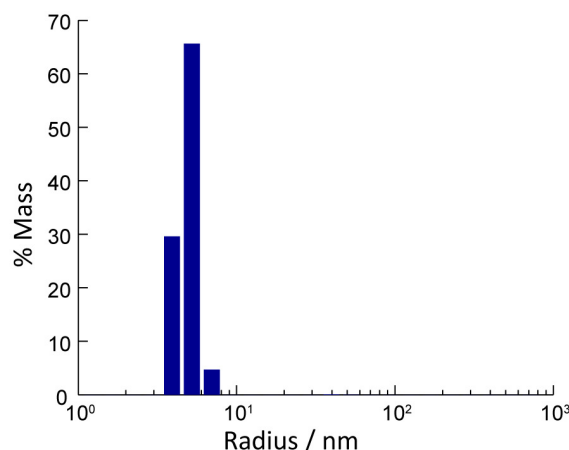

\begin{tabular}{llll}
\hline Item & $\mathbf{D}(\mathbf{n m})$ & \%Pd & \%Mass \\
\hline Peak 1 & 9.95 & 13.9 & 100
\end{tabular}

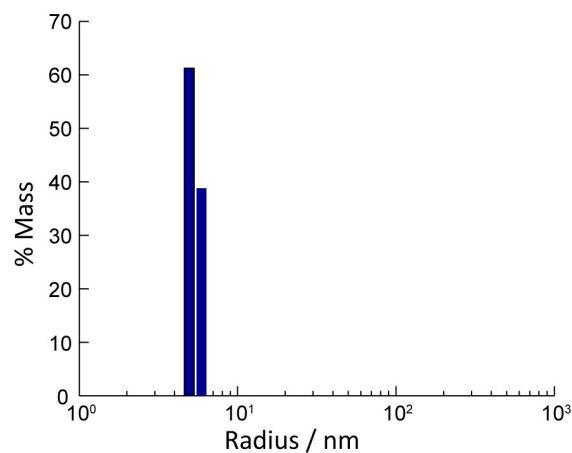

\begin{tabular}{llll}
\hline Item & $\mathbf{D}(\mathbf{n m})$ & \%Pd & \%Mass \\
\hline Peak 1 & 11.4 & 5.7 & 100
\end{tabular}

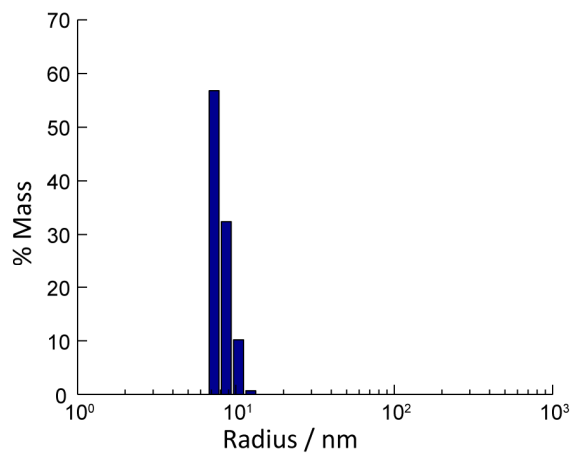

\begin{tabular}{llll}
\hline Item & $\mathbf{D}(\mathbf{n m})$ & \%Pd & \%Mass \\
\hline Peak 1 & 16.2 & 13.2 & 100.0
\end{tabular}

Figure S2. Size determination of QD HD by dynamic light scattering. (A) $565 \mathrm{~nm}$ carboxyQDs. (B) $605 \mathrm{~nm}$ carboxyQDs. (C) Commercial amine functionalized, PEGylated QDs emitting at $525 \mathrm{~nm}$ (Invitrogen part no. Q22041, component A). Left: measured autocorrelation function (blue) with fit to theory (purple). Vertical lines indicate limits used for fitting. Right: histogram with table showing peak positions (D, diameter; \%Pd, polydispersity, showing average of triplicate runs). 


\section{pH Stability of carboxyQDs and $20 \%$ aminoQDs}
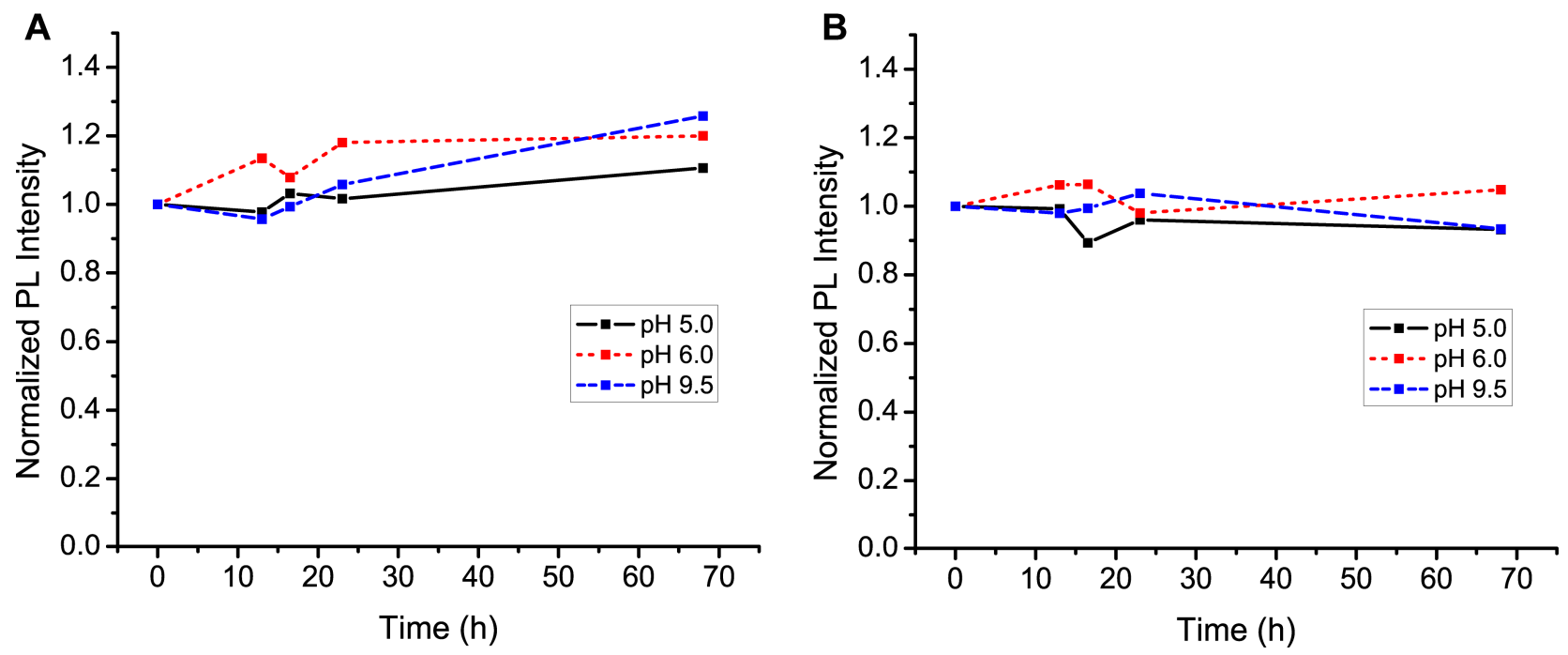

Figure S3. pH stability test of (A) carboxyQDs and (B) $20 \%$ aminoQDs (with $80 \%$ hydroxyPEG by mole ratio) at $\mathrm{pH} 5.0(-), 6.0(\cdots)$, and $9.5(---)$. 


\section{Fluorescamine-aminoQD Emission}
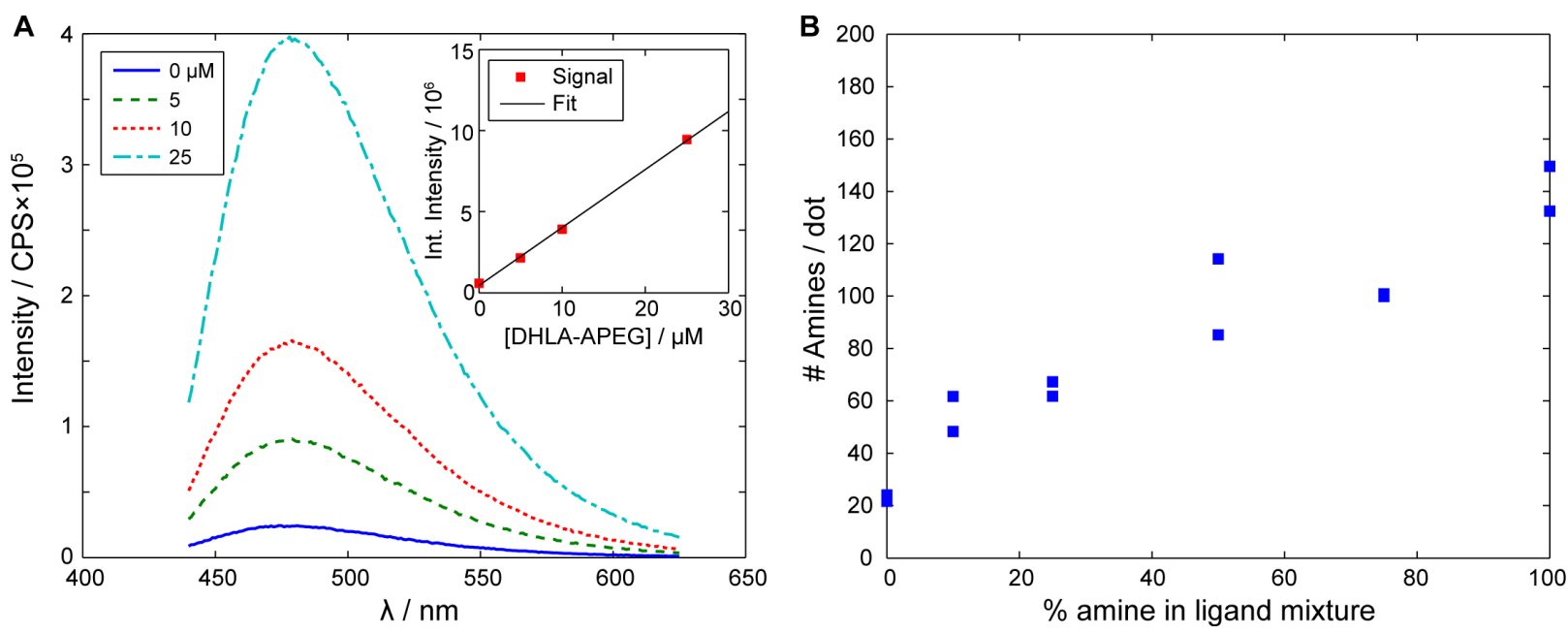

Figure S4. Measuring the number of aminoPEG per QD (558 nm emission). (A) Calibration: emission spectra of aminoPEG free ligand solutions in DMF after treatment with fluorescamine (380 nm excitation). Inset: integrated fluorescence intensity of these samples from $460-485 \mathrm{~nm}$, along with a linear fit. (B) Ratio of detected amine concentration to QD concentration versus wt $\%$ of amine-terminated ligand in aminoPEG/hydroxyPEG ligand exchange mixtures. Samples were run in duplicate to improve accuracy (in some cases values overlap). 


\section{Spectroscopy of $20 \%$ aminoQD-carboxy-X-rhodamine conjugate}

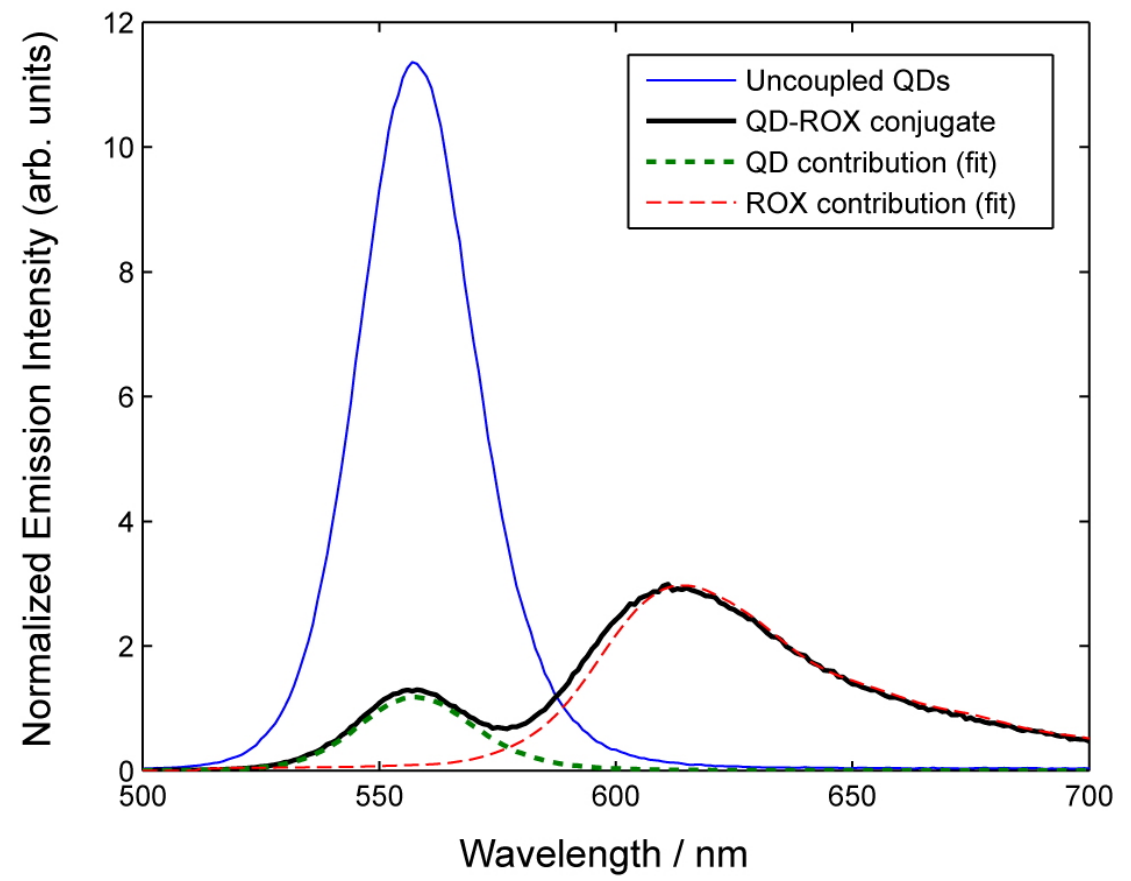

Figure S5. Emission spectra of purified QD-ROX conjugate described in the text and of a matching sample prepared with no dye. The spectra have been normalized according to the QD concentration in each sample so that the emission intensities may be directly compared. Fitting the emission spectrum of the conjugate as a linear combination of QD and dye components reveals a quench of the QD emission intensity by approximately $90 \%$ versus that in the absence of the ROX dye. 


\section{Conjugation of wild-type streptavidin to $20 \%$ aminoQDs}

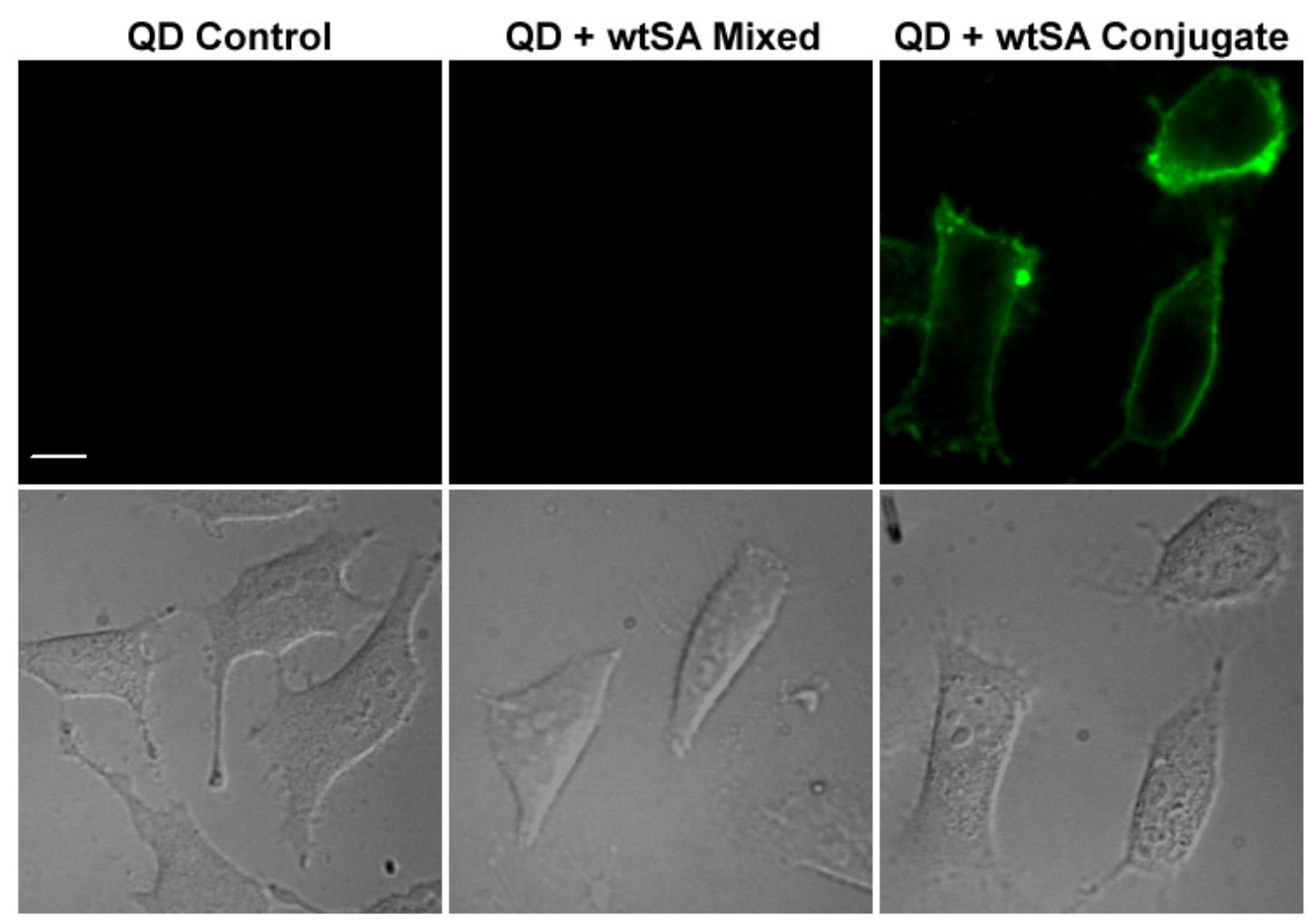

Figure S6. Testing for non-specific interactions between 20\% aminoQDs and wtSA. HeLa cells were nonspecifically biotinylated with biotin-sulfo-NHS and then incubated with $20 \%$ aminoQDs (left), $20 \%$ aminoQDs mixed with wtSA (middle), and $20 \%$ aminoQDs conjugated to wtSA using EDC/Sulfo-NHS (right). Top: fluorescence image at $565 \mathrm{~nm}$. Bottom: DIC image. Scale bar, $5 \mu \mathrm{m}$. 


\section{Spectroscopy of $20 \%$ aminoQD-Alexa Fluor 568 conjugate}
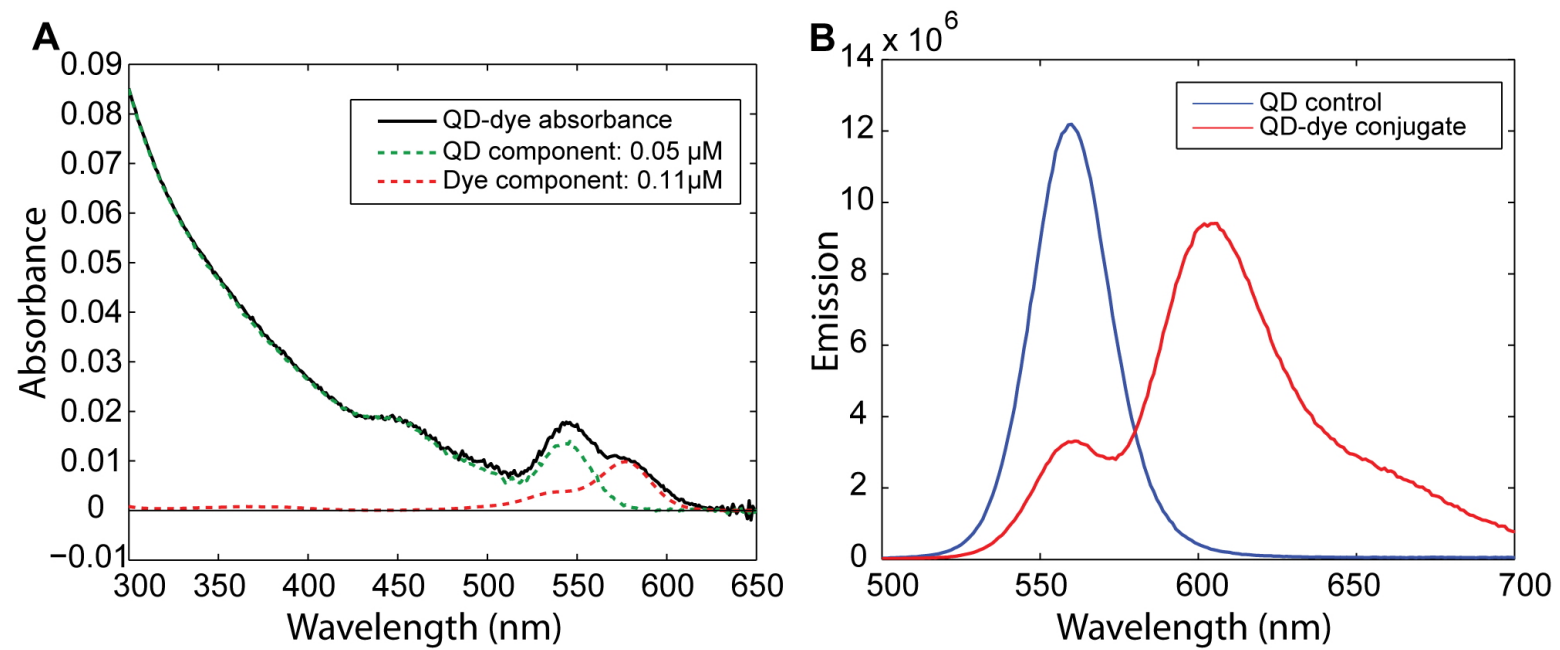

Figure S7. Spectral characterization for $20 \%$ aminoQDs-Alexa Fluor 568 conjugates. (A) Absorbance spectra for QD-dye conjugate fit as a linear combination of QD and dye components; Dye:QD ratio 2.3. (B) Emission spectrum of aminoQD and QD-dye conjugates. 


\section{QD-Dye Conjugate Targeting EGF Receptor}

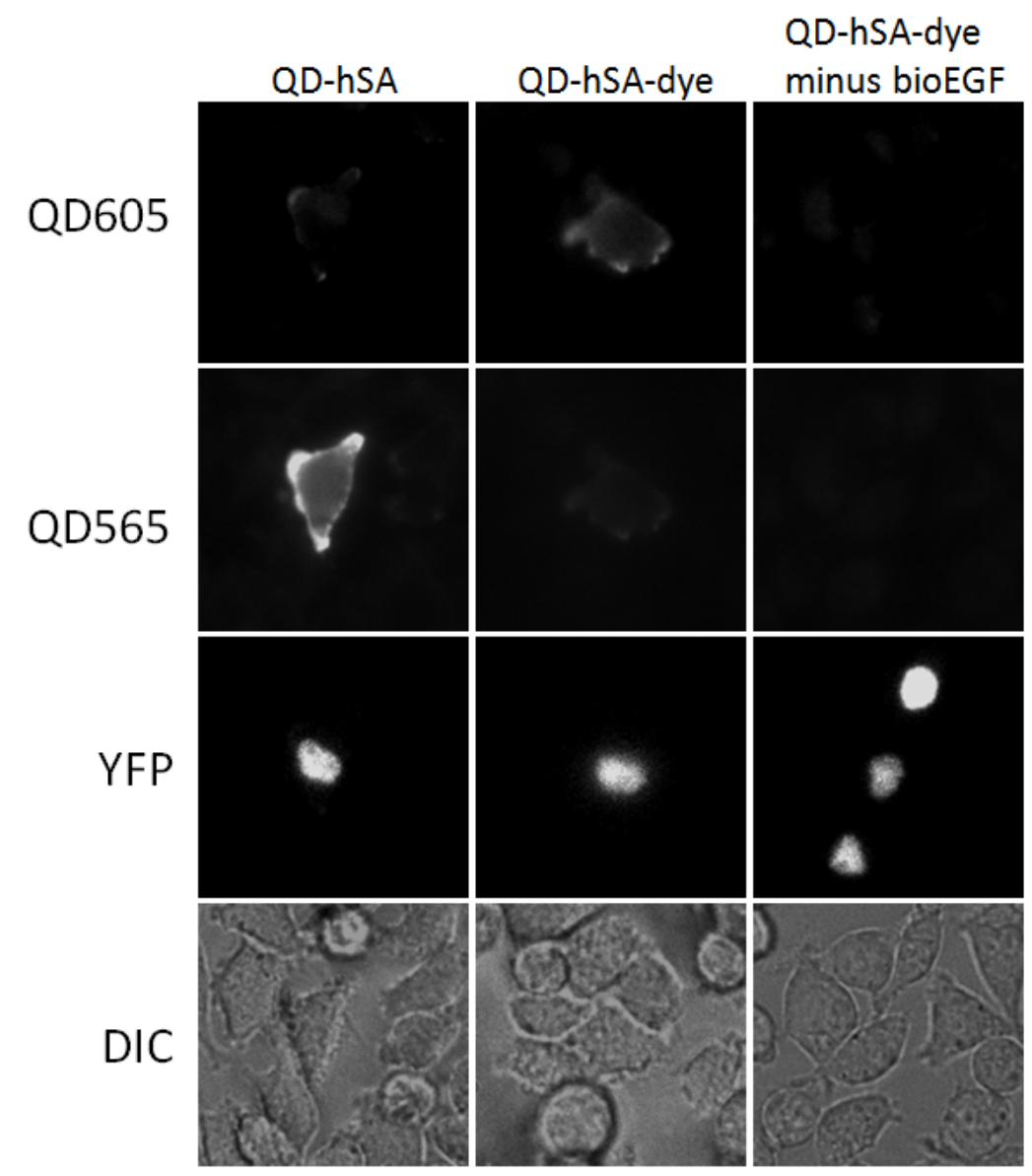

Figure S8. Targeting EGF receptor with 20\% aminoQD-hSA-dye conjugate, showing individual channels: $605 \mathrm{~nm}$ (dye emission), $565 \mathrm{~nm}$ (QD emission), YFP (transfection marker), and differential interference contrast (DIC) image. 


\section{Receptor tracking with single QD conjugates}

Movie S1. File name: SPT_EGF.avi

COS7 cells transfected with EGFR and BFP were labeled with biotinylated EGF and then $20 \%$ aminoQDSA. QD mobility was imaged at $37^{\circ} \mathrm{C}$. The movie is sped up 5x. Individual QDs are seen, as indicated by their brightness and blinking kinetics. Brighter spots represent clusters of QDs. Some QDs undergo rapid

movement in a consistent direction (Box 1 and 2), indicative of active transport of EGFR in vesicles inside the cell after internalization. 


\section{Diamino-PEG Spectra (Compound 1)}

ESI-MS $[M+H]+$

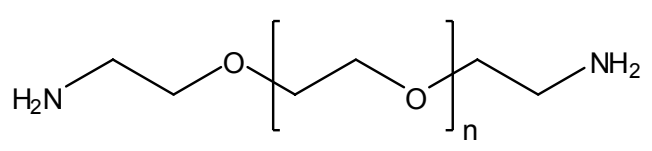

Chemical Formula: $\mathrm{C}_{20} \mathrm{H}_{44} \mathrm{~N}_{2} \mathrm{O}_{9}$

Molecular Weight $(\mathrm{n}=8)$ : 456.57

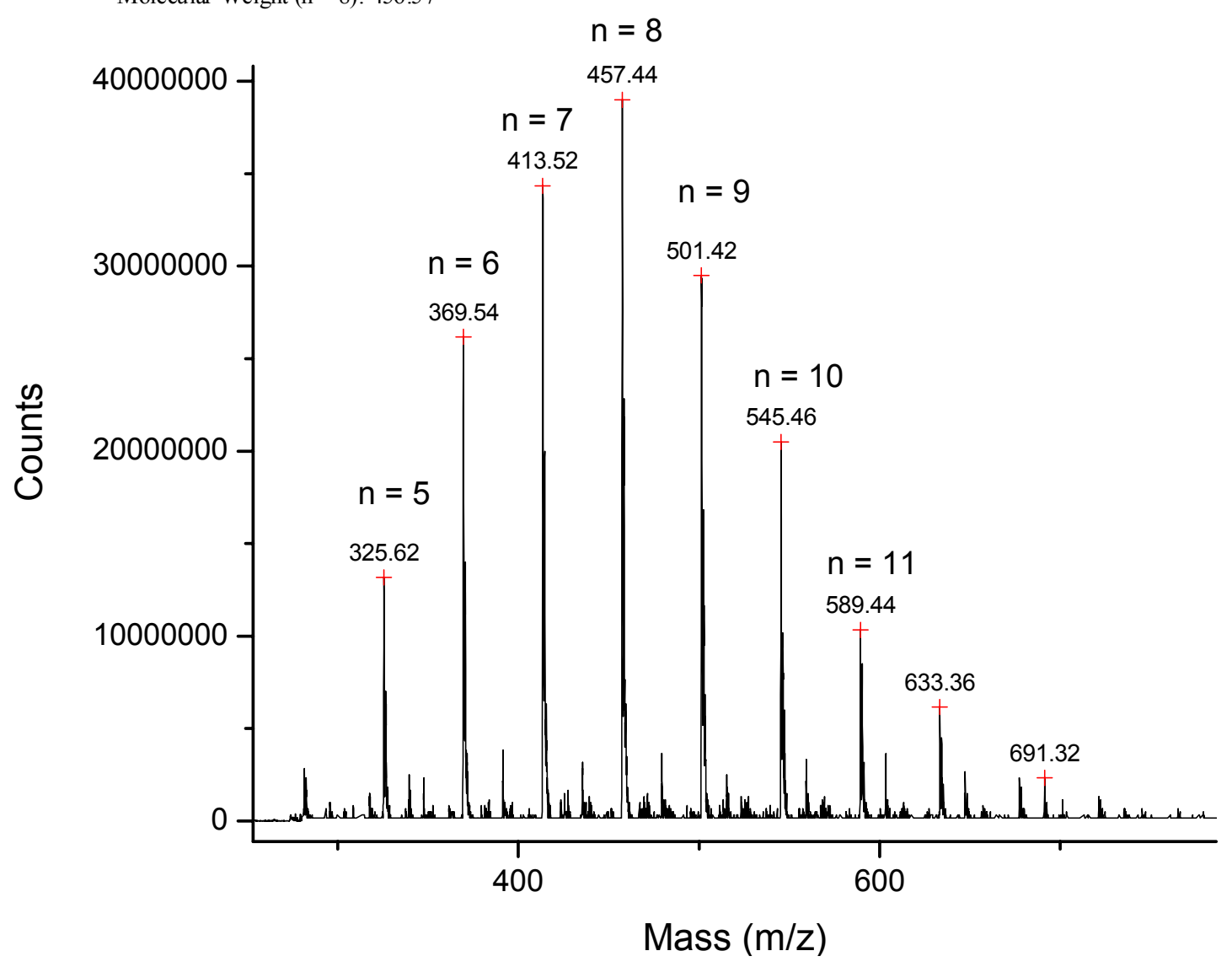


${ }^{1} \mathrm{H}-\mathrm{NMR}$ (compound 1)

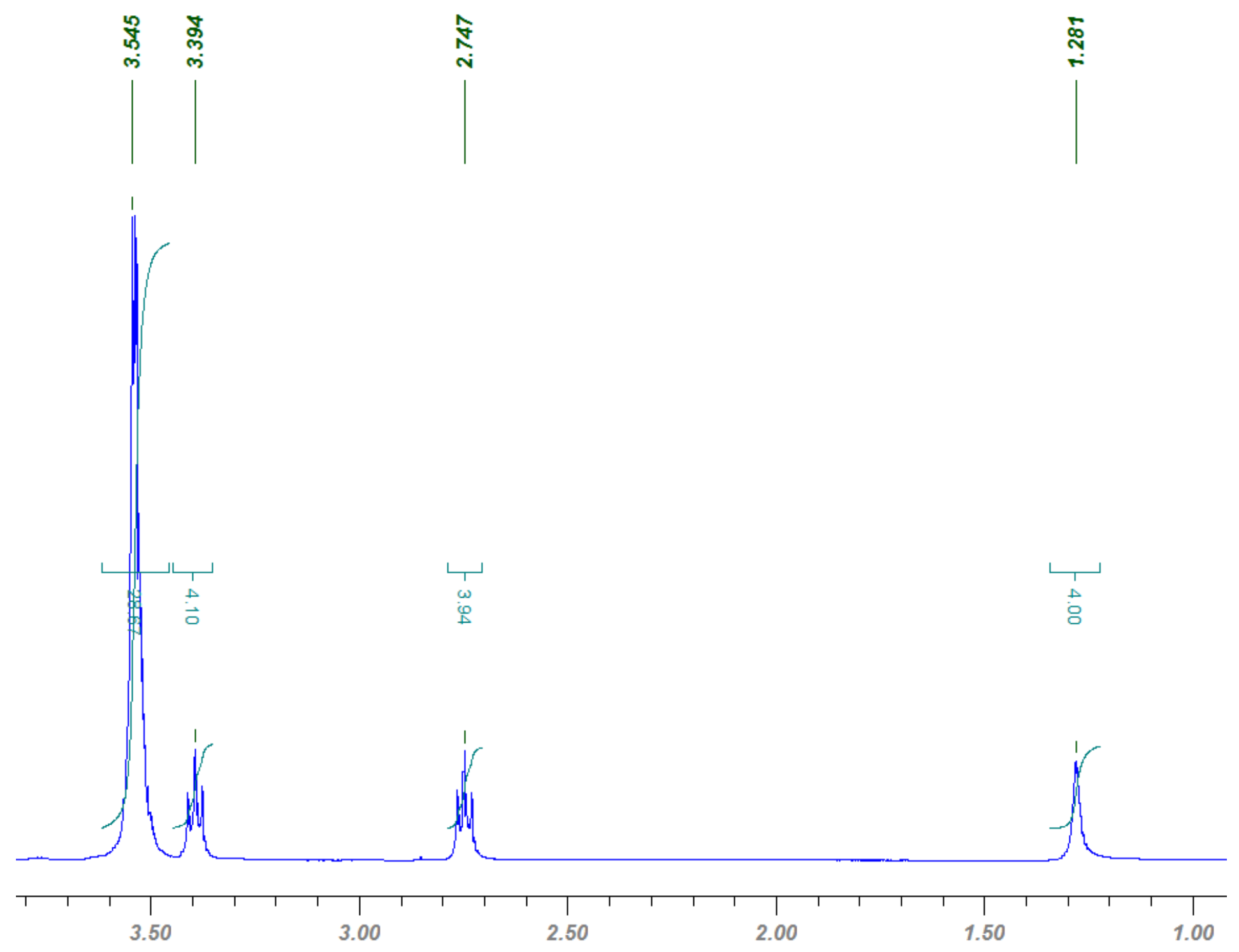




\section{LA-NHS Spectra}

${ }^{1} \mathrm{H}-\mathrm{NMR}$
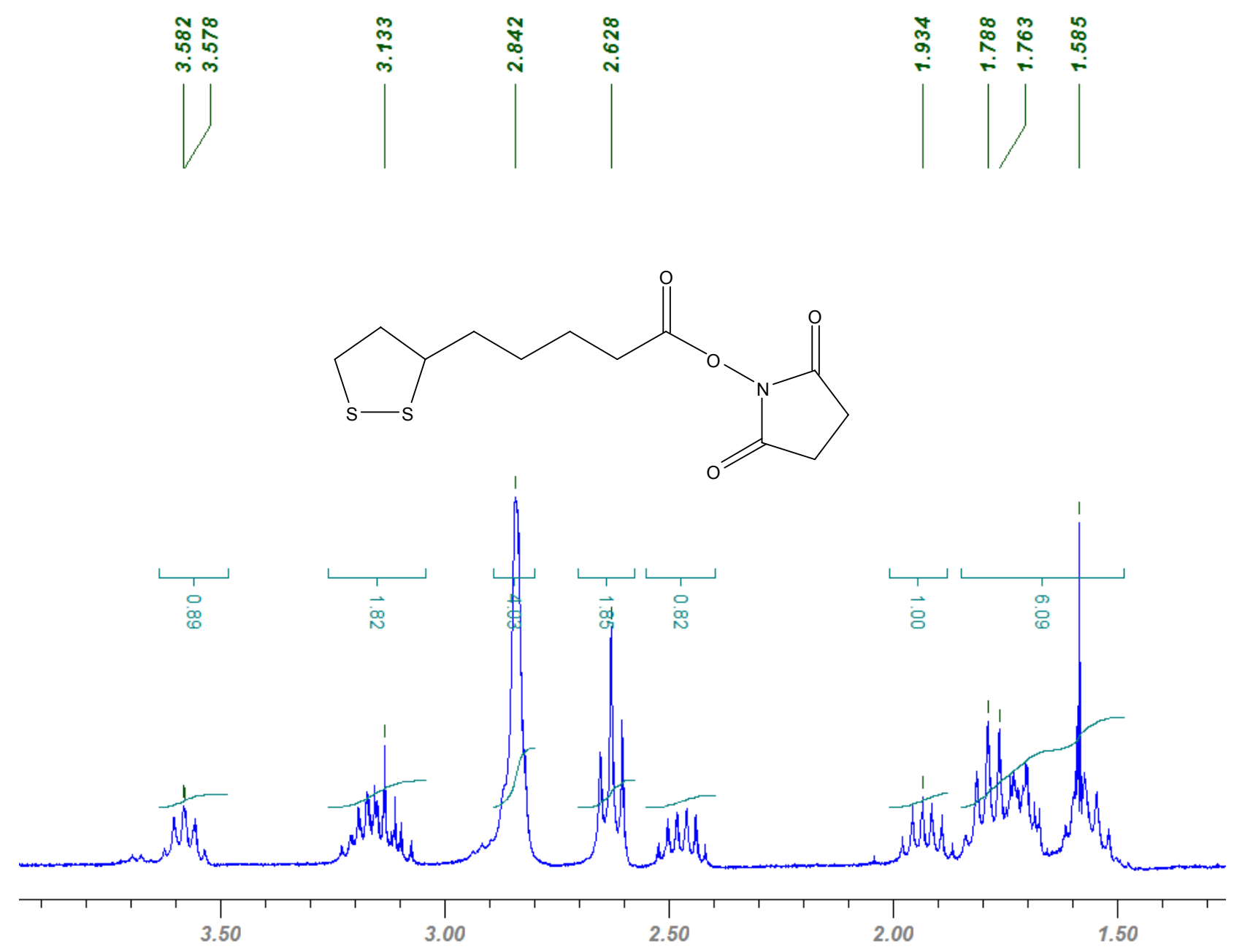

ppm 


\section{LA-PEG-NH ${ }_{2}$ Spectra (Compound 2)}

ESI-MS $[\mathrm{M}+\mathrm{H}]+$

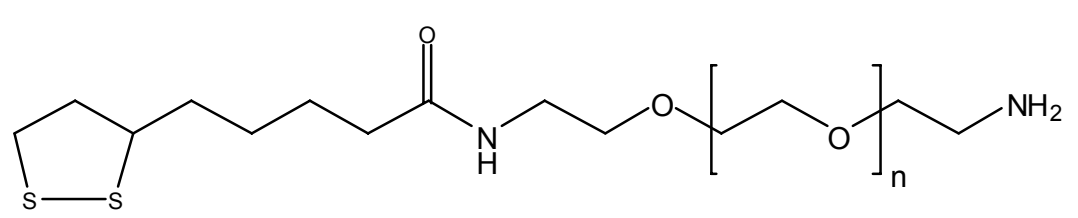

Chemical Formula: $\mathrm{C}_{28} \mathrm{H}_{56} \mathrm{~N}_{2} \mathrm{O}_{10} \mathrm{~S}_{2}$

Molecular Weight $(n=8): 644.88$

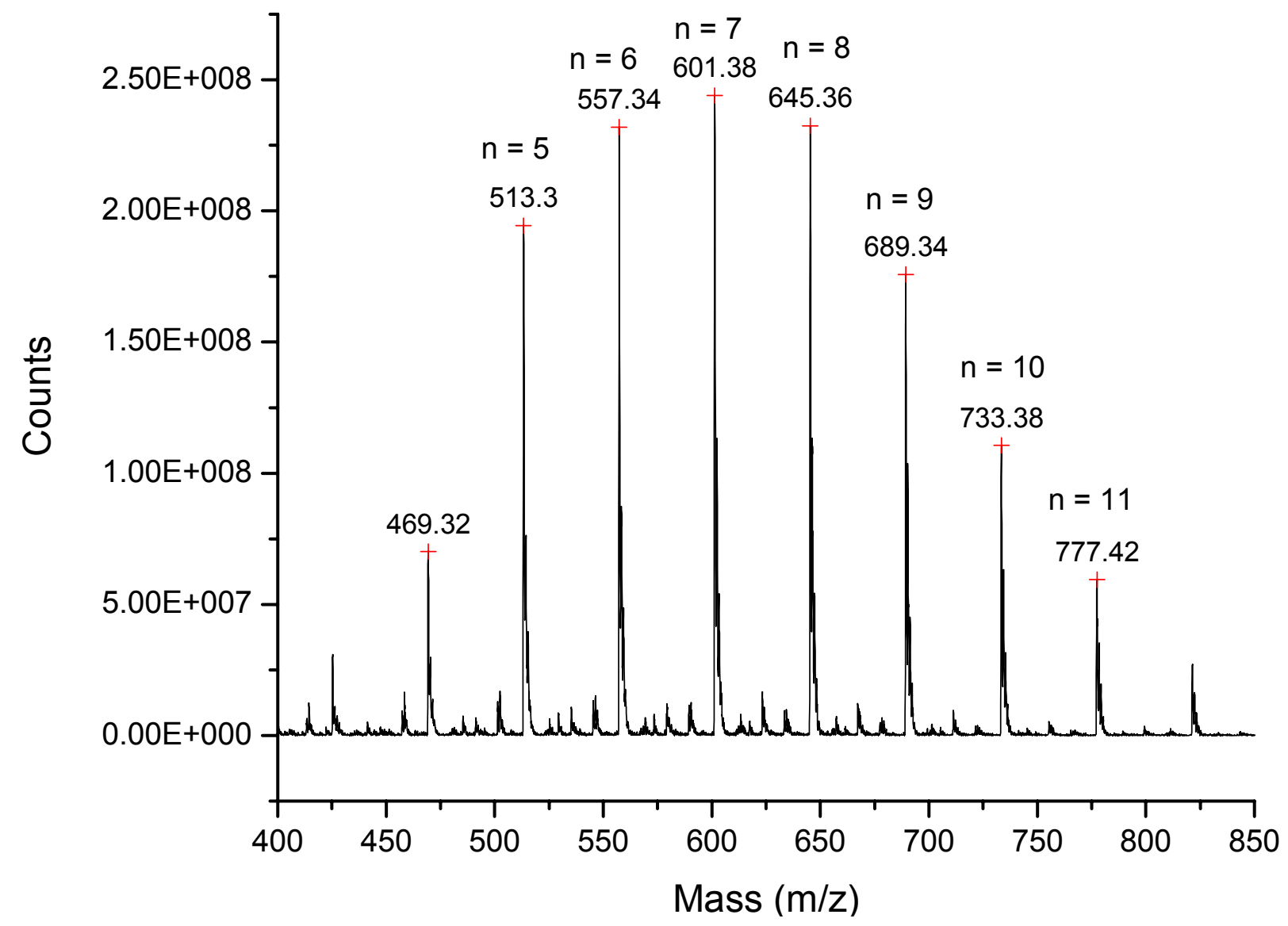


${ }^{1} \mathrm{H}-\mathrm{NMR}$ (compound 2)

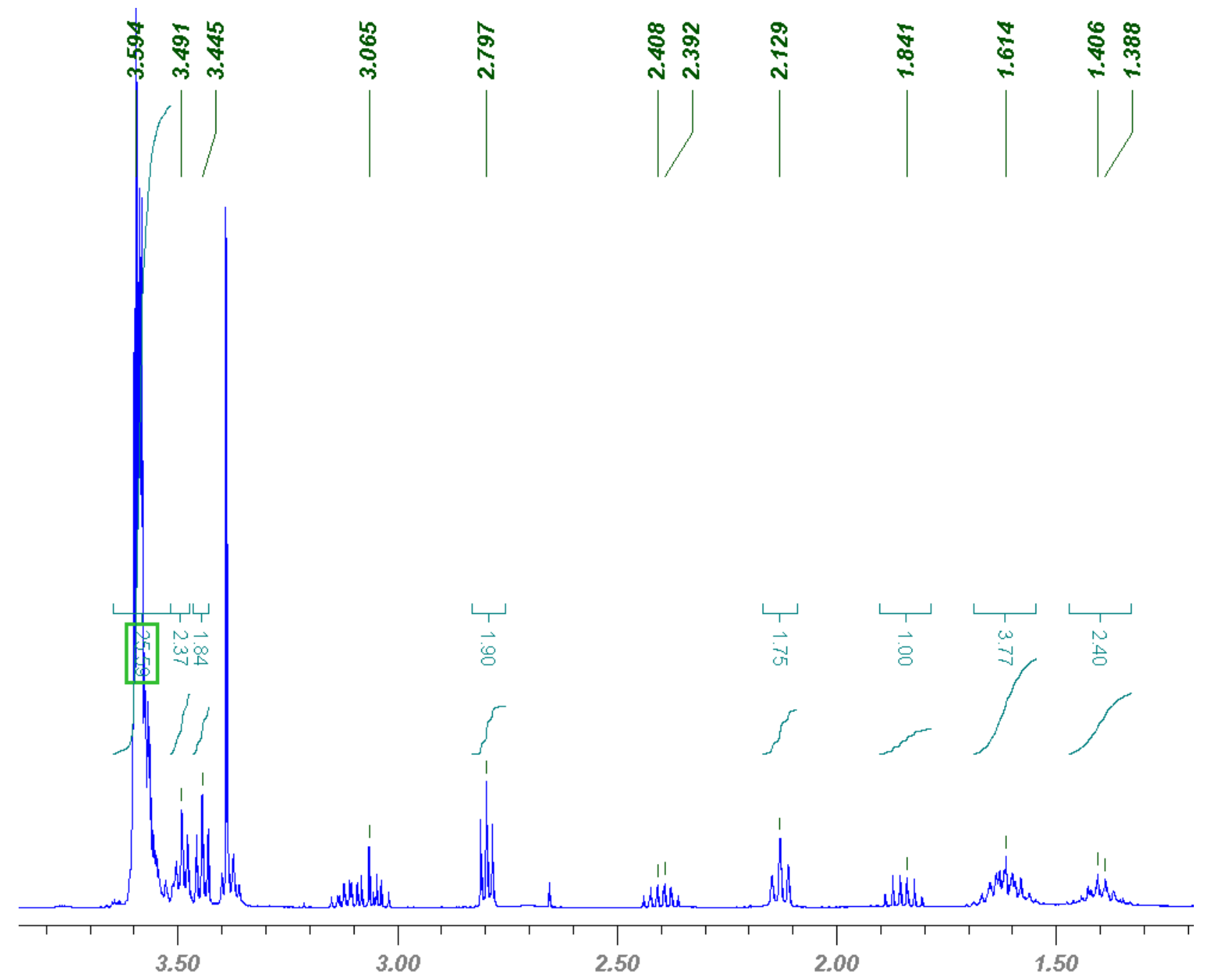

ppm 


\section{aminoPEG Spectra (Compound 3)}

ESI-MS $[\mathrm{M}+\mathrm{H}]^{+}$

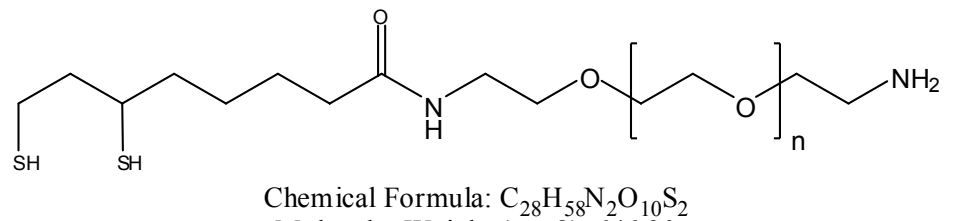

Chemical Formula: $\mathrm{C}_{28} \mathrm{H}_{58} \mathrm{~N}_{2} \mathrm{O}_{10} \mathrm{~S}_{2}$
Molecular Weight $(\mathrm{n}=8): 646.90$

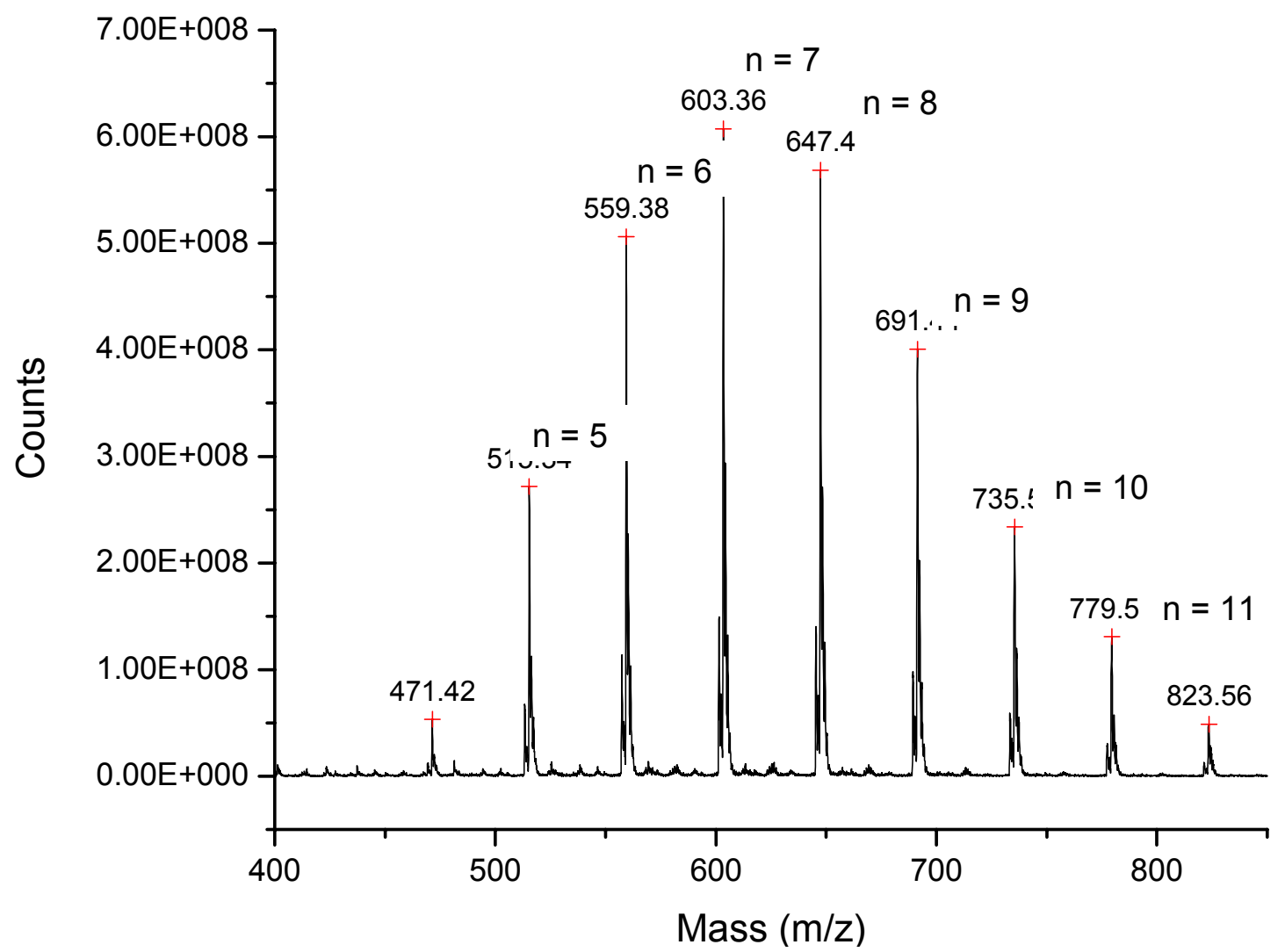


${ }^{1} \mathrm{H}-\mathrm{NMR}$ (compound 3)

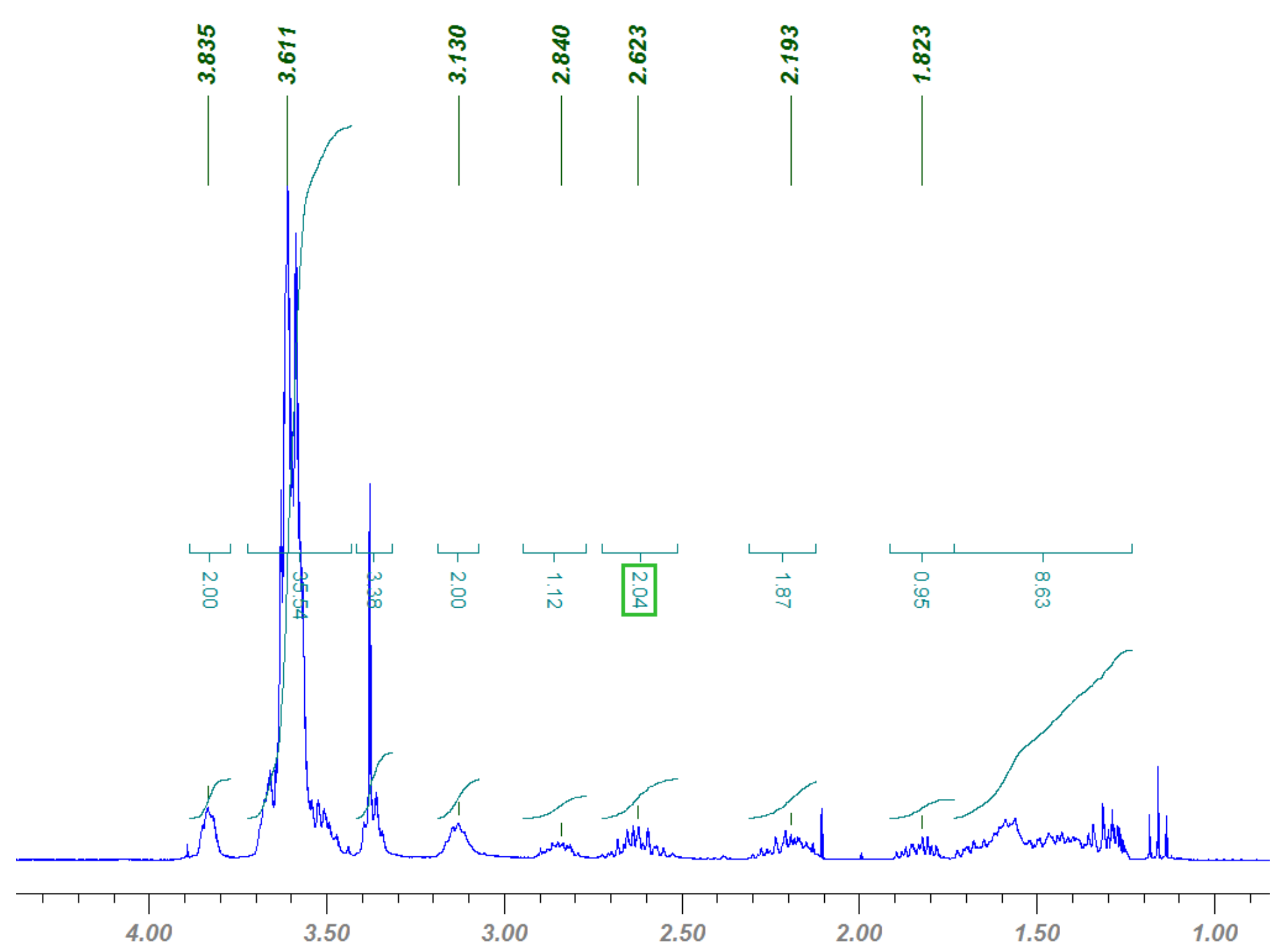

ppm 
LA-PEG- $\mathrm{CO}_{2} \mathrm{H}$ Spectra (Compound 5)

ESI-MS [M-H]
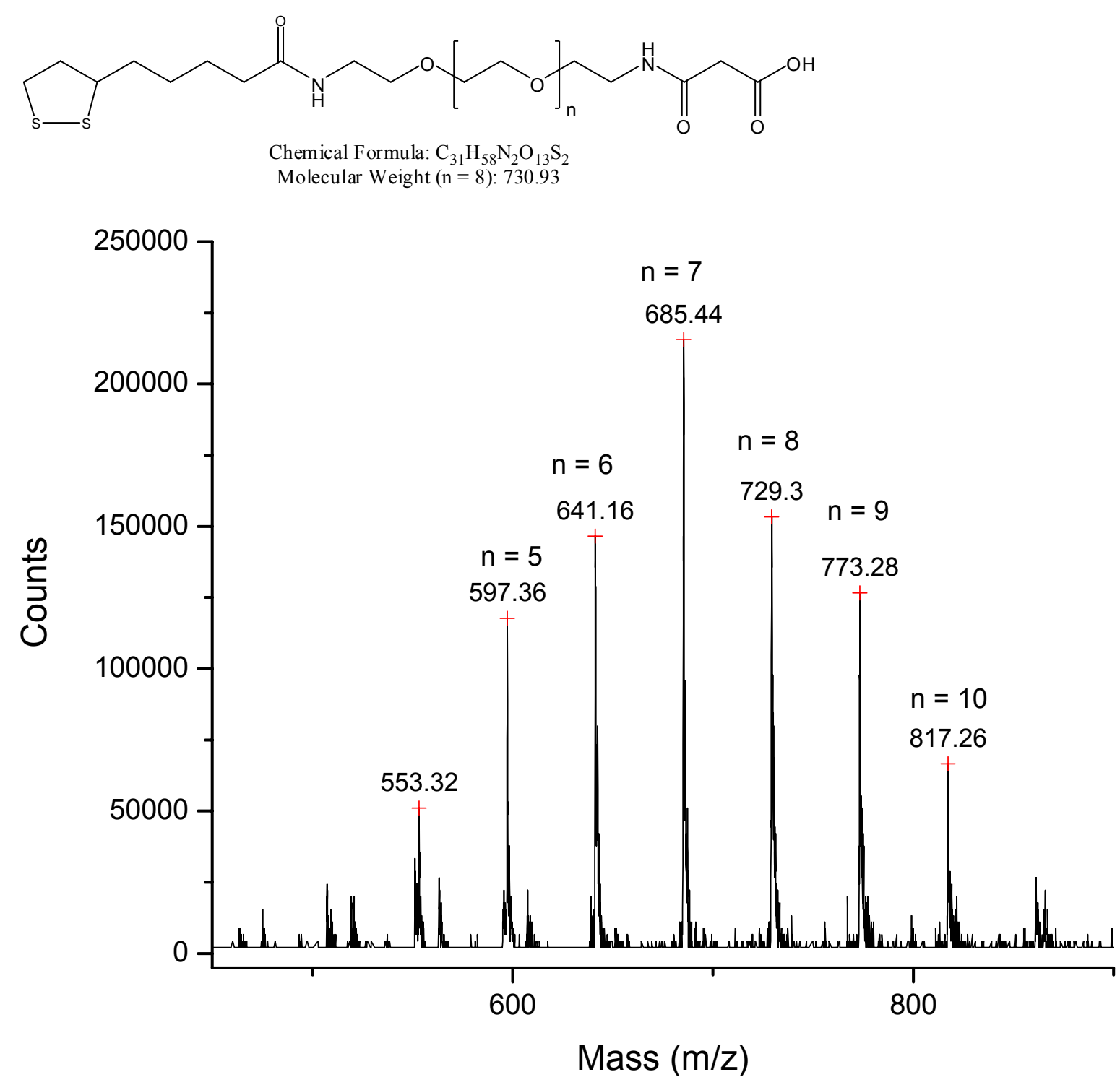


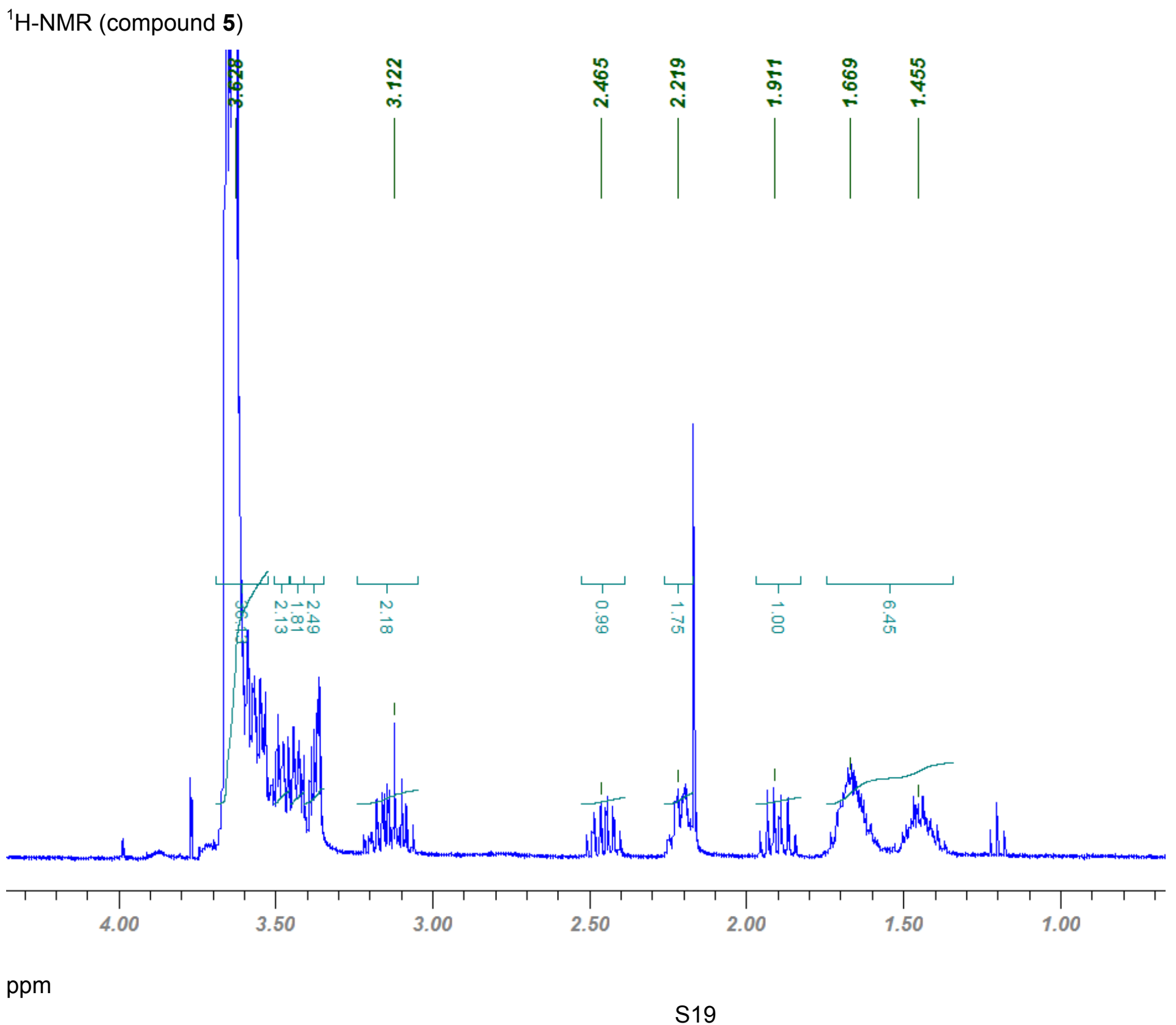




\section{carboxyPEG Spectra (Compound 6)}

ESI-MS [M-H]
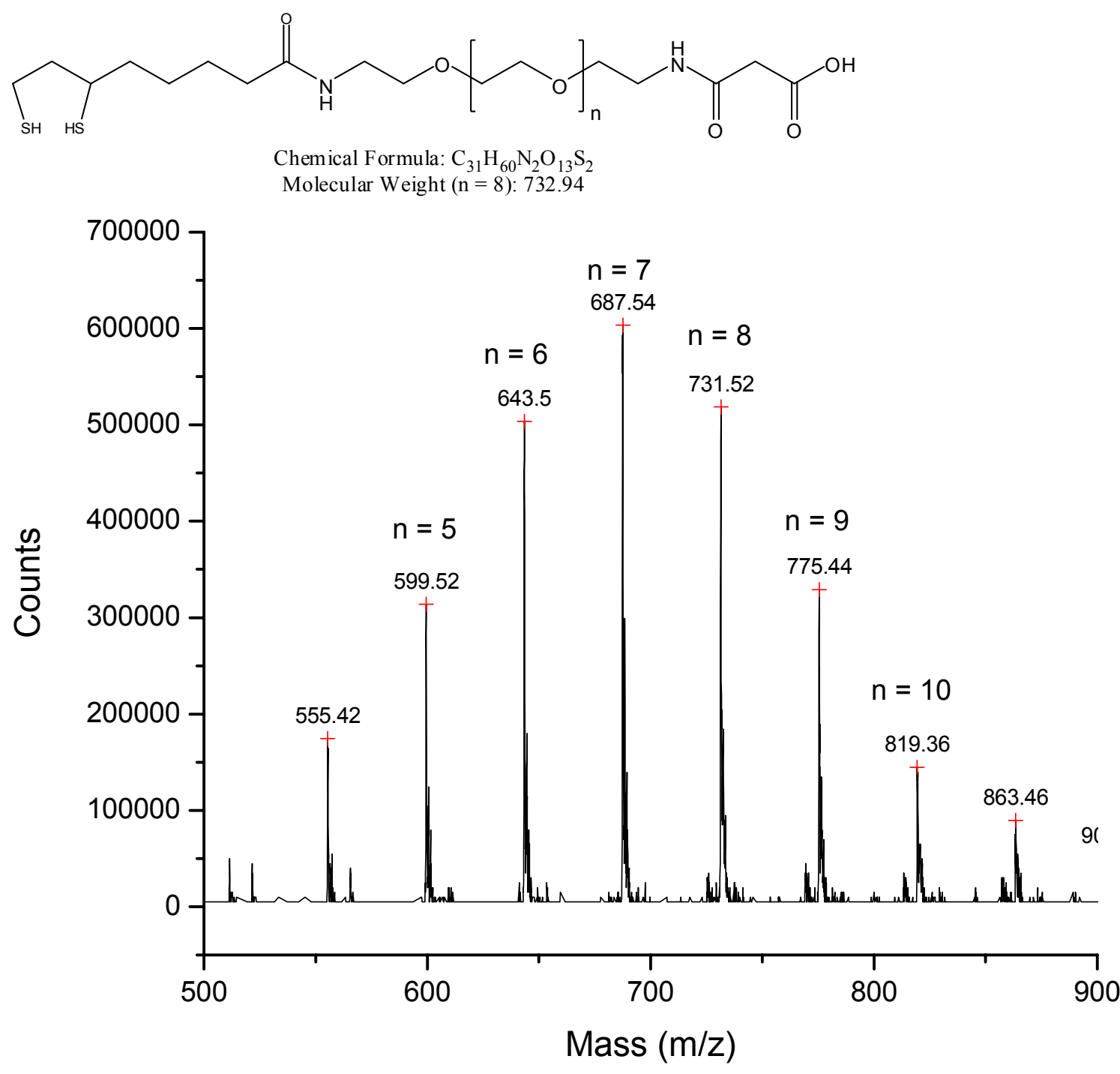
${ }^{1}$ H-NMR (compound 6)

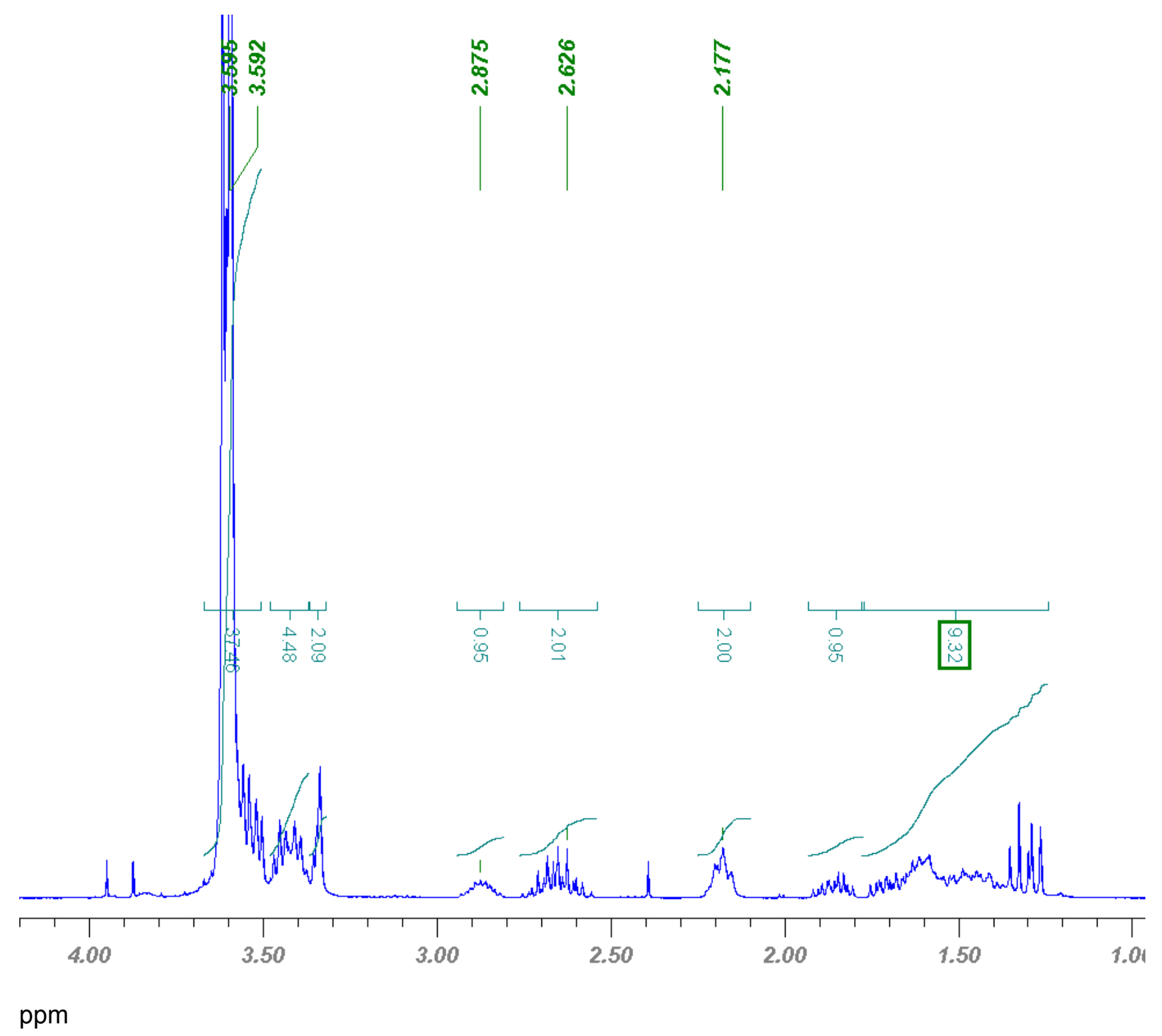

